\title{
The Implicit Beauty and Open Beauty of Tang Dynasty's Aesthetic Taste from Tang Dynasty Noble Women's Clothing Features
}

\author{
Li Wan \\ Department of Taxtile and Costume Design \\ Huanghe Science and Technology College \\ Zhengzhou, China
}

\begin{abstract}
The Tang Dynasty was a period when feudal society prosperous developed. At that time people's material life were very plentiful, thus brought their love for better life into the pursuit and praise of beauty. The women, especially the noble women because their particularity of gender and identity, at the time they gradually became a social beauty carrier. The notice and praise from men and even the whole society to noble women made them to search and create beauty from all kind of aspects. Clothing which are the best way to reflect the beauty connotation naturally became the best filed for these women to show and create beauty. Whether the early Tang's graceful narrow sleeve dress, or the dashing $\mathrm{Hu}$ Fu and Men's clothing in flourishing period of Tang Dynasty, all reflect Tang people, especially the Tang dynasty noble women's unique aesthetic vision in different periods. Overall, there are two aesthetic features of the Tang Dynasty noble women's clothing features: First is the implicit beauty under the influence of Confucian doctrine and feudal Etiquette ; Second is due to Tang people's appreciation of human body and more focus on realism, thus pay more attention to women's curves, so their clothing showed the healthy open beauty.
\end{abstract} open

Keywords—noble; women; clothing features; aesthetic; implicit;

\section{INTRODUCTION}

Tang Dynasty was a society which adores beauty, from the magnificent Tang three-color glazed pottery to the beautiful and harmonious Tang music dance, from the spiritual sculpture to the amazing calligraphy, Tang people's pursuit of beauty was self-evident. After a nation meets their basic survival needs, it is bound to turn into a higher life demand, which is the pursuit of a higher quality lifestyle. In Tang Dynasty the nation was prosperous and the people were strong and powerful, the culture was prosperous too, people can enjoy their lives, thus brought their love for better life into the pursuit and praise of beauty. The women, especially the noble women because their particularity of gender and identity, at the time they gradually became a social beauty carrier.

In Tang Dynasty, there were three combination changes for nobles women's clothing styles, include Slip Skirt, Hu Fu and women wear men's clothing. In early Tang period women 's clothing were mostly similar with Sui Dynasty, upper body wear a short sleeve jacket, lower body wear tight dress with the waistband up to the armpit and with silk ribbon tie, Slip Skirt appeared as early as the Spring and Autumn Period, in Han Dynasty it began to become popular among the Central Plains's Han women, in the thousands of years history development, although it has been impacted by other species popular clothing, but always maintain Slip Skirt this basic style and it became the typical clothing of Han Women in feudal society; in flourishing period of Tang Dynasty, $\mathrm{Hu} \mathrm{Fu}$ from the exotic area, with its new clothing styles favored by the majority of noble women, especially the Uighur ethnic clothing styles was quite popular among the noble women. Under this influence, women wear men's clothing also was in vogue for a time; since the late Tang Dynasty, $\mathrm{Hu}$ Fu fashion was fade, more traditional Han clothing restored, the improved Slip Skirt clothing with big sleeves again became the major clothing for women. From these styles which lead the clothing trends at the time, we could not only see the prosperity, splendid, broad and free clothing culture, but also we can see the influence to women's clothing caused by Tang's aesthetic taste. Overall, there are two aesthetic features of the Tang Dynasty noble women's clothing features: First is the implicit beauty under the influence of Confucian doctrine and feudal Etiquette ; Second is due to Tang people's appreciation of human body and more focus on realism, thus pay more attention to women's curves, so their clothing showed the healthy open beauty.

\section{TANG DYNASTY WOMEN ClOTHING WITH "IMPLICIT BEAUTY" FEATURE-SLIP SKIRT AND HALF-SLEEVES}

Slip Skirt started from the Warring States period with physical evidence, and ended by the "TifaYifu" of the late Ming and early Qing Dynasty, it is the most basic form of Chinese traditional Han clothing. During 2000 years, although there may be changes about the length and width, but the basic shape has maintained the original style. This is inseparable with the unified and fixed requirements of women's clothing in ancient Chinese ritual system. Compared with other clothing shapes, Slip Skirt has a distinct feature: short shirt, long skirt, up and down ratio reflects the golden section requirement, with a rich aesthetic connotation. 
In early Tang period women's clothing were mostly similar with Sui Dynasty. Jacket, shirt, coat, skirt were the daily clothing of Tang Dynasty's women. Slip skirt naturally was the major clothing for Tang Dynasty women. In the Sui Dynasty and early Tang period, women's short jacket are small sleeve, lower body wear tight-fitting skirt, skirt waist tied very high, generally above the waist, some even up to the armpit, and tied with ribbon band "Fig. 1". Slip skirt has a distinct feature: short shirt, long skirt, up and down ratio reflects the golden section requirement, with a rich aesthetic connotation.

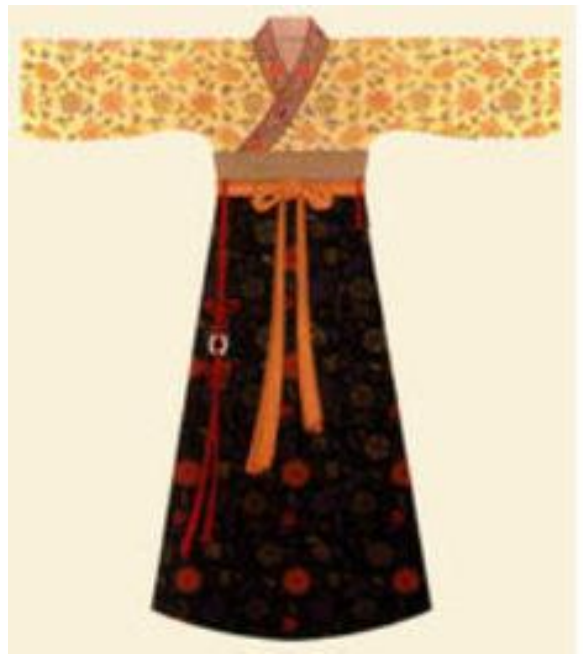

Fig. 1. Cross collar slip skirt.

Half-sleeves, also known as "short-sleeve" is a costume comes from short jacket. It was the very common new clothing style Tang Dynasty women's clothing "Fig. 2". It is generally short-sleeved, double-breasted, with the length of waist, and ligaments in the chest. Also there is a "pullover" type, wear from the head. The lower hem of the half-sleeves can appear out, also can be in the skirt like the short jacket. Usually it wears together with the slip skirt.

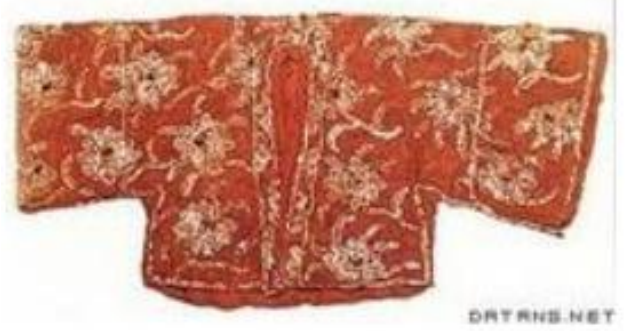

Fig. 2. Half-sleeves

Half-sleeves type matches with slip skirt made women's clothing has more levels and the three dimensional sense of clothing was also stronger. We can see from the picture, whether it is a single slip skirt or the slip skirt matched with half-sleeves, the body wrap range is very comprehensive. In addition to the head and hands, no other parts of the body exposed (this is also the basic requirement of women's clothing in the whole feudal society). But this conservative clothing style express the body curve by the high waistband, so that women's body presented as a pretty slender sense, elegant and refined like "a lotus flower just rose from the water". This dress just reflected the conservative and implicative aesthetic requirements in feudal society. Plus brocade and Gong Tao, Tang Dynasty women's clothing presented the long and short contrast and the layers dressing effect, the beauty of level of this clothing will fully expressed the oriental implicit beauty which there may be an end of the words but not to their message.

\section{TANG DYNASTY WOMEN CLOTHING WITH OPEN BEAUTY" FEATURE-Hu Fu, WOMEN WEAR MEN'S Clothing and Flat Collar Design}

Tang Dynasty is after China experienced the Sixteen Kingdoms to the Northern and Southern Dynasties nearly three centuries of upheaval and ethnic migration, after the big fusion, built in the basis of Sui Dynasty temporary unity. Hu and Han ethnic fusion and penetration already exceeded the single, inherited traditional pattern, national compatibility of $\mathrm{Hu}$ and $\mathrm{Han}$ in Tang Dynasty has become a reality. Therefore, $\mathrm{Hu} \mathrm{Fu}$ has enormous influence at the time. Wearing $\mathrm{Hu} \mathrm{Fu}$ is often a fashion performance for noble woman "Fig. 3". In Tang Xuanzong Kaiyuan, $\mathrm{Hu} \mathrm{Fu}$ was in vogue, both men and women wearing $\mathrm{Hu} \mathrm{Fu}$ and $\mathrm{Hu}$ cap. $\mathrm{Hu}$ Fu's popularity not only because Tang clothing absorb the impact from foreign culture, but also because in contrast with traditional women's clothing, $\mathrm{Hu} \mathrm{Fu}$ did not have strict hierarchy and political, convenient and free, comfort and both men and women can wear. It is not only novel and unique, but also relatively fit the body which could accentuate the curve of women's body parts, thus has the attraction which cannot be resisted. The Han traditional clothing in the same period tend to be more particular about the political class and social etiquette, which seems boring to Tang people. Hu Fu in comparison indeed has more features.

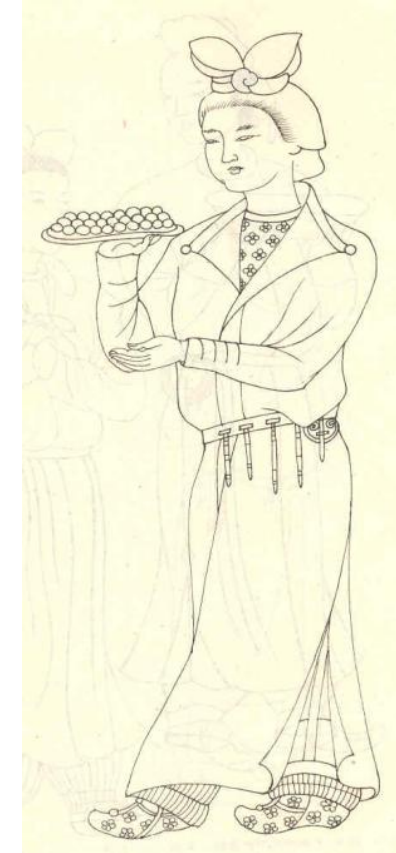

Fig. 3. Maidservant with $\mathrm{Hu} \mathrm{Fu}$ 
Tang Dynasty woman while in pursuit of light, elegant and show the physical beauty, also showed a very strong interest for the clothing which reflect men's masculine quality. Women disguised as men has also become one of the features of Tang Dynasty costumes. From the painted terracotta female stand figurines unearthed from the Tang Taizong Zhaoling tomb in Shaanxi Liquan, you can see the image of woman disguised as a man, she wore $\mathrm{Pu}$ Tou on her head and round neck gown with tight sleeves, with belt. For a chic capable image "Fig. 4", women wear men's clothes in China's long feudal society that is extremely rare. "Liji Neize" already states: "Men and women have different clothes" Women wear men's clothes will be considered as lacking in virtue and regarded as the demon suit, Tang Dynasty has this open dressing style is under the special situation of feminist consciousness rising, conversely this phenomenon's emergence is a reflection of the open and compact of Tang society.

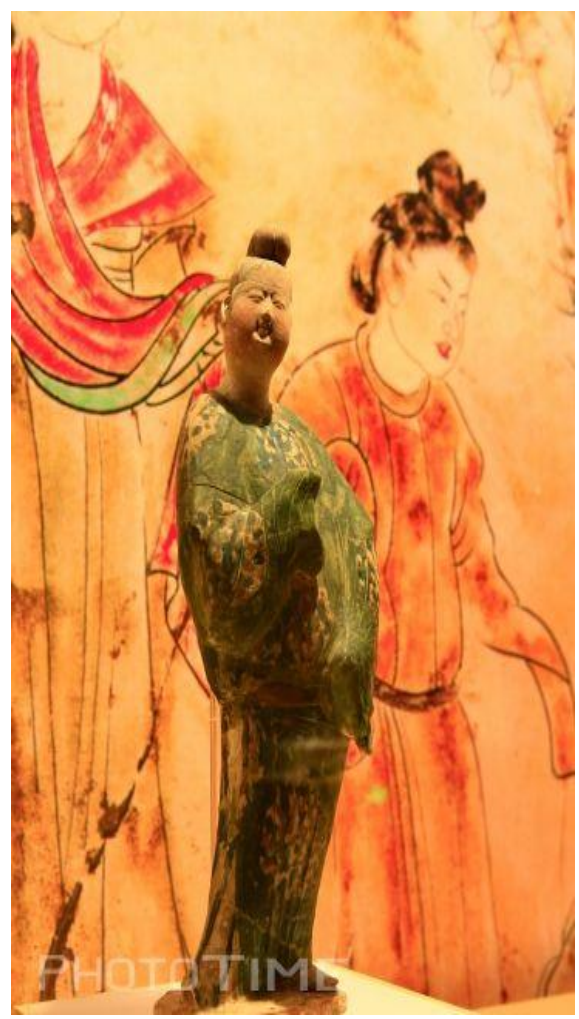

Fig. 4. Tang Dynasty. Figurines of women in men's clothes.

Consider fullness as beauty, open as fashion were the aesthetic characteristics of Tang people, and the Tang Dynasty secular landlord class and the civil class had the same aesthetic taste, so from the Tang Dynasty they pushed the appreciation of fullness as beauty to the extreme, there were a lot of paintings with this fuller figured women image. The appreciation of plump body made the noble women clothing in addition to $\mathrm{Hu} \mathrm{Fu}$ and men's clothes, also fully absorbed the features of early Tang's slip skirt with tight sleeves and produced new costume type: topless dress with big sleeves, which consists of large-sleeved shirt and high waist skirt. It is topless pullover type, collar opened very low, with no underwear inside, half breast exposed outside, and in order to fully highlight the beautiful plump curves, women tend to use veil texture for skirt, embroidered with flowers on it, strapless and backless, revealed the delicate skin from the mantle. This is the most daring style of ancient Chinese women's clothing, which is enough to see the open extent of the social and mind at that time. It is worth mentioning that this topless dress only noble women was allowed to wear, ordinary woman clothes were still conservative.

In Chinese feudal society, women have been always tied to the shackles of traditional propriety, the so-called " smile without teeth", "walk without the dress move", "stand without lean the door" ,"go out without expose the face" and so on all have been regarded as the rules and prohibitions that a woman must strictly abide, Tang noble women made bold attempts in order to get rid of this yoke, from the capable $\mathrm{Hu} \mathrm{Fu}$, men's clothes to ecstasy and sexy topless dress with big sleeves, while the pursuit of clothing with open beauty, they were also gradually get rid of the spirit shackles of feudal ethics, they make clear look at their beautiful and real faces.

\section{CAUSES OF THE "IMPlicit BEAUTY" AND "OPEN BEAUTY" IN TANG DYNASTY AESTHETIC CONCEPT}

Tang was undoubtedly an extremely prosperous period of feudal society development. But no matter how rich of their material life, Tang Dynasty society under the rule of Han has always followed Confucian tradition ethics which formed since the Qin and Han Dynasty. Confucianism advocates "Etiquette". Such as the strict classification, gender-etiquette, and poor and rich, high and low, old and young, close and distant all have their own etiquette etc., and so many etiquette doctrines made the whole feudal society people thought was being detained. Conservative and implicit became the aesthetic mainstream of the whole Chinese feudal era. This aesthetic also reflected in the clothing. The women with generally low social status were bound by many rules and prohibitions. The most direct manifestation is the choice of clothing must be complete, conservative with strong blocking function. This is the main reason why slip skirt was able to throughout the feudal society in the 2000 years. Because this customs which tightly wrapped body in line with the conservative and implicit aesthetic requirements of women's clothing in feudal society.

But why did so many novel and chic even exaggerated sexy women's clothing styles appear only in the Tang Dynasty. This is primarily related with the historical conditions at that time. Tang Dynasty was the rising period of feudal society, the powerful national strength and advanced culture created the condition for people's pursuit of life enjoyment, feminist consciousness was rose in this particular era: the social status of women has improved significantly, some noble women even got the same political rights with men, in Tang Dynasty not only appeared a series of political events which caused by court women like Shangguan Waner, Empress Wei and Princess Taiping, but also created the only female emperor $\mathrm{Wu}$ Zetian in China's history. The objective existence of women in politics in a way to strengthen the common respect psychology for women in society. This situation made the Tang women especially noble women bolder and opener in thinking and behavior. Compared to other dynasty' women, they had more courage to pursue individuality. As Hegel said, 
the nature power of human is to be reproduced or implemented in a subject, then to the subject of aesthetic activities, they fund themselves and meet their demands through aesthetic experience, and found their nature power in the aesthetic object. Free and open social atmosphere provided the free aesthetic pursuit to Tang Dynasty women. They desired their values could be recognized by society, and expected the rights and status which get equal treatment with men, so that they carried out a bold attempt in the clothing, and the new aesthetic interest emerged.

In China's feudal society, only Tang Dynasty made vividly combination between tradition and innovation, implicit and open ideology. From Tang Taizong to Tang Xuanzong these more than one hundred years, Tang people presented the boundless, no reluctant creations and innovations, in clothing it reflected as the vigorous aesthetic consciousness. Hegel said in "Aesthetics": "Art shows by itself and directed beyond itself to some spiritual things which it want to express." Colorful clothing as an aesthetic object, it accumulated Chinese thoughts, emotions and spirit. Tang nobles women's clothing from the early Tang 's implicit morbidezza to the open and freely wearing $\mathrm{Hu} \mathrm{Fu}$ and men's clothes in the flourishing period of Tang Dynasty, it just experienced the a shift in social aesthetic interest. Clothing styles of different periods reflect the political and cultural atmosphere of different periods, more importantly, through the review of Tang noble women's clothing, we can see: what kind of change and shock does the Tang people's mind and emotions experienced, their aesthetic ideas and aesthetic ideals also accumulated, nurtured and infected the future generations, showing its permanent charm.

\section{REFERENCES}

[1] Hua Mei. Clothing and Chinese Culture [M] Beijing: Beijing People's Publishing Company, 2001.01.

[2] Shen Congwen. Chinese ancient costumes research [M] Beijing: Commercial Press, 2011.12.

[3] Ye Shangqing. Chinese art masterpieces appreciation [M] Shanghai: Shanghai People's Publishing Company, 1984.02.

[4] Ye Licheng. Clothing aesthetics [M] Beijing: China Textile Press, 2001.01.

[5] Hegel. Aesthetics Volume one [M] Beijing: Commercial Press, 1997.07. 